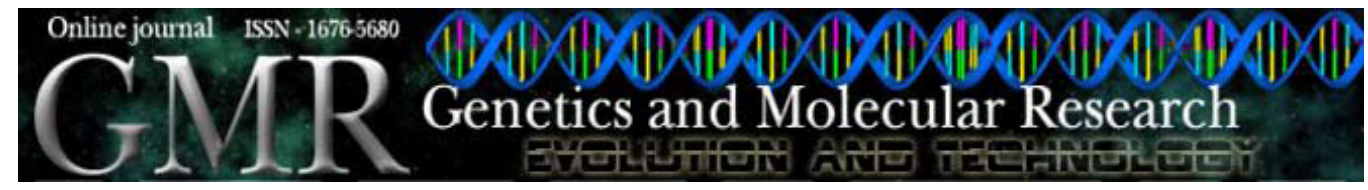

\title{
Karyological features of wild and cultivated forms of myrtle (Myrtus communis, Myrtaceae)
}

\author{
S. Serçe ${ }^{1}$, E. Ekbiç ${ }^{2}$ J. Suda ${ }^{3}$, K. Gündüz ${ }^{1}$ and Y. Kiyga ${ }^{1}$ \\ ${ }^{1}$ Department of Horticulture, Faculty of Agriculture, \\ Mustafa Kemal University, Antakya, Hatay, Turkey \\ ${ }^{2}$ Kahta Vocational School, Adiyaman University, Adiyaman, Turkey \\ ${ }^{3}$ Department of Botany, Faculty of Science, Charles University in Prague, \\ Prague, Czech Republic and Institute of Botany, \\ Academy of Sciences of the Czech Republic, Průhonice, Czech Republic \\ Corresponding author: S. Serçe \\ E-mail: sedatserce@gmail.com
}

Genet. Mol. Res. 9 (1): 429-433 (2010)

Received November 29,2009

Accepted January 4, 2010

Published March 9, 2010

\begin{abstract}
Myrtle is an evergreen shrub or small tree widespread throughout the Mediterranean region. In Turkey, both cultivated and wild forms, differing in plant and fruit size and fruit composition, can be found. These differences may have resulted from the domestication of the cultivated form over a long period of time. We investigated whether wild and cultivated forms of myrtle differ in karyological features (i.e., number of somatic chromosomes and relative genome size). We sampled two wild forms and six cultivated types of myrtle. All the samples had the same chromosome number $(2 n=2 x=22)$. The results were confirmed by 4',6-diamidino-2-phenylindole (DAPI) flow cytometry. Only negligible variation $(\sim 3 \%)$ in relative fluorescence intensity was observed among the different myrtle accessions, with wild genotypes having the smallest values. We concluded that despite considerable morphological differentiation, cultivated and wild myrtle genotypes in Turkey have similar karyological features.
\end{abstract}

Key words: Chromosome number; Flow cytometry; Polyploidy; Myrtle 


\section{INTRODUCTION}

Myrtle, Myrtus communis L. (Myrtaceae), is a diploid $(2 n=2 x=22)$ (Canhoto et al., 1999) woody plant native to southern Europe and North Africa. Being widespread throughout the Mediterranean region, the species is one of the most important evergreen shrubs in the Mediterranean maquis. Their leaves are 3-5 cm long and contain tannins, flavonoids and volatile oils (Baytop, 1999). Myrtle has been used for medical, food and spice purposes since ancient times. Other uses of its leaves include cattle feed, production of liqueur, cut foliage, and potted plants (Bruna et al., 2007). The flowers have five petals and sepals, with a large number of stamens. They are pollinated by insects, and birds are the most common agent of seed dispersal, although some mammals have been reported to consume and disperse their seeds, as well (Aronne and Russo, 1997). Flower biology including secretory cavities, unicellular papillae and hair trichomes have also been studied morphologically, anatomically and histochemically (Ciccarelli et al., 2008).

There are two major fruit morphologies based on fruit color, i.e., whether dark or white. In the dark form, the fruits turn pale yellow and eventually dark blue on maturation during mid-fall to early winter. On the other hand, the fruit either remains white or turns pale yellow, but never turns blue in the white-fruited form. The dark-colored form is far more common than the white-colored one. This color polymorphism has been reported for many regions (Traveset et al., 2001).

In Turkey, myrtle is widespread in the Mediterranean and Aegean regions (Baytop, 1997). Myrtle leaves as well as fruits have been used as an antiseptic medicine in villages, while essential oil from leaves is utilized in perfumery (Baytop, 1999). Both color morphs are present in Turkey, with the white morph being rare just as in other countries. In addition, there are also cultivated white-colored types, which yield much larger fruits than their wild counterparts. In Turkish, the wild form is called "mersin" or "murt", while the cultivated form is called "hambeles". There are small orchards in Hatay where this crop is marketed locally as table fruits. These orchards are established by seedling-grown plants since myrtle cuttings are highly subject to rot when they are prepared during the winter (Klein et al., 2000).

Polyploidy, i.e., the presence of more than two genomes per cell, has long been recognized as an important force in plant evolution. Recent estimates suggest that about $70 \%$ of angiosperms and up to $95 \%$ of pteridophytes underwent one or more rounds of genome duplication in their evolutionary history (Soltis and Soltis, 1999). The incidence of polyploidy in crop plants may be even higher. For example, Grant (1963) estimated that 78\% of crop species are polyploid. When compared to their diploid counterparts, polyploids usually have larger cell size, increased enzyme activity and higher heterozygosity (Hancock, 2005).

The objective of this study was to assess whether wild and cultivated forms of myrtle, differing considerably in plant and fruit characteristics, also show divergence in karyological features such as the number of somatic chromosomes and relative genome size (i.e., whether or not genome duplication played a role in myrtle domestication).

\section{MATERIAL AND METHODS}

Two forms of myrtle genotypes were studied: i) cultivated types with large, white-colored fruits (Nos. 31-01, 31-02, 31-03, 31-06, 31-07, and 31-08), and ii) wild genotypes with small, dark-colored (31-04) and white (31-05) fruits. The genotypes were sampled from the Hatay Province located in the eastern part of the Mediterranean region of Turkey. The horticultural practices 
in cultivated forms were limited to pruning and training, weed management, and soil cultivation. To evaluate the fruit characteristics, 100 mature berries were harvested from each of three randomly selected plants in October 2007. Fruits and their seeds were weighed using a balance with a precision of $\pm 0.01 \mathrm{~g}$. Fruit size and seed cavity size were measured using a digital caliper. Total soluble solids and titratable acidity were assessed in juice obtained from 100 fruits per sample. Total soluble solids content was determined with a refractometer (Atago, Model ATC-1E) and titratable acidity by titration of $5 \mathrm{~mL}$ fruit juice with $0.1 \mathrm{~N} \mathrm{NaOH}, \mathrm{pH} 8.1$, and expressed as $\mathrm{g}$ malic acid per $100 \mathrm{~mL}$ juice. Juice $\mathrm{pH}$ was measured using a $\mathrm{pH}$-meter (InoLab, Model WTW).

For chromosome counting, several cuttings from each genotype were first rooted, and newly formed roots were used in the analysis. The cytogenetic analysis was conducted according to Canhoto et al. (1999). At least 10 independent metaphase spreads of each sample were examined. Relative fluorescence intensity (relative genome size) was determined in fresh leaf samples using 4',6-diamidino-2-phenylindole (DAPI) flow cytometry as described by Suda et al. (2007). Glycine max L. 'Polanka' (2C = 2.50 pg; Doležel et al., 1994) was selected as an internal reference standard. Glycine max was selected since it is a well-established standard with reliably determined genome size and low level of secondary metabolites, giving high-resolution histograms; it has a genome size suitable for analyses of myrtle, which does not overlap with that of myrtle and is not substantially different, avoiding potential instrument non-linearity.

\section{RESULTS AND DISCUSSION}

The results of the fruit characteristics are summarized in Table 1. Obviously, there was a considerable variation within both cultivated and wild genotypes, with coefficient of variation $(\mathrm{CV})$ values ranging from 7 to $33 \%$ and 2 to $13 \%$, respectively. For example, the mean fruit weight in the cultivated genotype 31-08 was only $8.3 \mathrm{~g}$ while that of 31-07 was nearly 2 -fold higher $(16.3 \mathrm{~g})$. Similarly, the fruit length within the cultivated genotypes ranged from $12.9 \mathrm{~mm}(31-08)$ to $16.8 \mathrm{~mm}(31-07)$. In addition, mean acidity in cultivated genotypes also varied more than 2-fold (1.6-3.7\%). Considerable differences were also observed between the two wild genotypes studied. For example, fruit weight in 31-05 was higher than in 31-04 (3.5 vs $2.8 \mathrm{~g})$, and the weight of 10 seeds followed the same pattern $(0.8 v s 0.5 \mathrm{~g})$.

\begin{tabular}{|c|c|c|c|c|c|c|c|c|c|}
\hline Genotype & $\begin{array}{c}\text { Fruit } \\
\text { weight }(\mathrm{g})\end{array}$ & $\begin{array}{c}\text { Fruit } \\
\text { width }(\mathrm{mm})\end{array}$ & $\begin{array}{c}\text { Fruit } \\
\text { length }(\mathrm{mm})\end{array}$ & $\begin{array}{l}\text { Seed cavity } \\
\text { width }(\mathrm{mm})\end{array}$ & $\begin{array}{l}\text { Seed cavity } \\
\text { length (mm) }\end{array}$ & $\begin{array}{l}\text { Seed weight } \\
\text { (g/10 seeds) }\end{array}$ & $\begin{array}{c}\text { Soluble } \\
\text { solids (\%) }\end{array}$ & $\mathrm{pH}$ & Acidity \\
\hline \multicolumn{10}{|l|}{ Cultivated } \\
\hline $31-01$ & $12.3 \pm 0.1$ & $12.0 \pm 0.6$ & $14.7 \pm 0.2$ & $7.8 \pm 0.3$ & $8.5 \pm 0.2$ & $1.3 \pm 0.1$ & $15.8 \pm 0.8$ & $5.0 \pm 0.1$ & $3.3 \pm 0.3$ \\
\hline $31-02$ & $14.5 \pm 0.8$ & $12.1 \pm 0.3$ & $15.3 \pm 0.4$ & $8.5 \pm 0.3$ & $9.2 \pm 0.3$ & $1.7 \pm 0.2$ & $15.5 \pm 1.0$ & $5.3 \pm 0.1$ & $2.5 \pm 0.1$ \\
\hline $31-03$ & $10.3 \pm 0.3$ & $12.1 \pm 0.3$ & $14.6 \pm 0.1$ & $7.6 \pm 0.1$ & $8.2 \pm 0.2$ & $1.3 \pm 0.1$ & $17.6 \pm 0.1$ & $5.8 \pm 0.1$ & $3.6 \pm 0.3$ \\
\hline $31-06$ & $14.9 \pm 0.6$ & $13.5 \pm 0.2$ & $16.6 \pm 0.3$ & $8.6 \pm 0.4$ & $9.6 \pm 0.3$ & $1.9 \pm 0.1$ & $18.6 \pm 0.5$ & $5.2 \pm 0.1$ & $3.7 \pm 0.4$ \\
\hline $31-07$ & $16.3 \pm 1.4$ & $13.7 \pm 0.2$ & $16.8 \pm 0.7$ & $8.3 \pm 0.3$ & $9.2 \pm 0.3$ & $1.9 \pm 0.1$ & $13.9 \pm 0.4$ & $6.0 \pm 0.1$ & $1.6 \pm 0.2$ \\
\hline $31-08$ & $8.3 \pm 0.3$ & $11.5 \pm 0.2$ & $12.9 \pm 0.3$ & $7.2 \pm 0.1$ & $7.9 \pm 0.1$ & $1.1 \pm 0.1$ & $12.6 \pm 0.1$ & $6.0 \pm 0.1$ & $1.6 \pm 0.1$ \\
\hline Mean & $12.8 \pm 2.9$ & $12.5 \pm 0.9$ & $15.2 \pm 1.4$ & $8.0 \pm 0.6$ & $8.8 \pm 0.7$ & $1.5 \pm 0.3$ & $15.7 \pm 2.2$ & $5.5 \pm 0.4$ & $2.7 \pm 0.9$ \\
\hline CV (\%) & 23 & 7 & 9 & 8 & 8 & 20 & 14 & 7 & 33 \\
\hline \multicolumn{10}{|l|}{ Wild } \\
\hline $31-04$ & $2.8 \pm 0.2$ & $7.9 \pm 0.2$ & $9.5 \pm 0.4$ & $5.5 \pm 0.2$ & $5.9 \pm 0.2$ & $0.5 \pm 0.1$ & $21.1 \pm 0.1$ & $5.9 \pm 0.1$ & $7.4 \pm 0.1$ \\
\hline $31-05$ & $3.5 \pm 0.1$ & $7.6 \pm 0.3$ & $10.4 \pm 0.1$ & $5.7 \pm 0.2$ & $6.7 \pm 0.3$ & $0.8 \pm 0.1$ & $14.9 \pm 0.0$ & $6.0 \pm 0.1$ & $6.6 \pm 0.1$ \\
\hline Mean & $3.2 \pm 0.4$ & $7.7 \pm 0.3$ & $9.9 \pm 0.5$ & $5.6 \pm 0.2$ & $6.3 \pm 0.5$ & $0.6 \pm 0.2$ & $18.0 \pm 4.4$ & $5.9 \pm 0.1$ & $7.0 \pm 0.6$ \\
\hline CV (\%) & 13 & 4 & 5 & 4 & 8 & 33 & 24 & 2 & 9 \\
\hline
\end{tabular}

$\mathrm{CV}=$ coefficient of variation. 
Regardless of the intra-group variation, the mean values of the measured characters unambiguously differed between wild and cultivated types, except for soluble solids and $\mathrm{pH}$. For instance, the mean fruit weight, width and length as well as seed weight of cultivated plants were much higher than those of wild genotypes. The mean size of the seed cavity was also larger for cultivated genotypes, albeit to a lesser extent compared to the aforementioned characters. However, mean acidity was about $40 \%$ lower in the cultivated group when compared to its wild counterpart. Indeed, the same accessions were previously compared based on pomological and molecular data (Serçe et al., 2008). The analyses unambiguously separated the wild and cultivated types, indicating a genetic differentiation between these accessions.

Somatic number of chromosomes and relative genome size were determined in all myrtle accessions. Figure 1 shows metaphase plates for both wild and cultivated plants. All genotypes had the same chromosome number $(2 n=2 x=22)$ regardless of type (i.e., wild $v s$ cultivated and/or white- $v s$ dark-fruited). Flow cytometric analyses yielded histograms with two distinct peaks corresponding to the myrtle sample and internal reference standard (Figure 2).

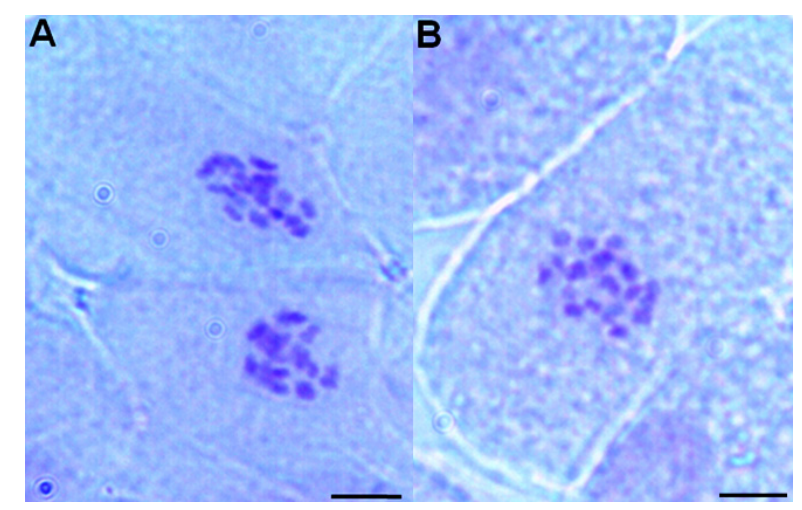

Figure 1. Metaphase chromosomes of cultivated (No. 31-01) and wild (No. 31-04) myrtle genotypes. Bars indicate $5.00 \mu \mathrm{m}$.

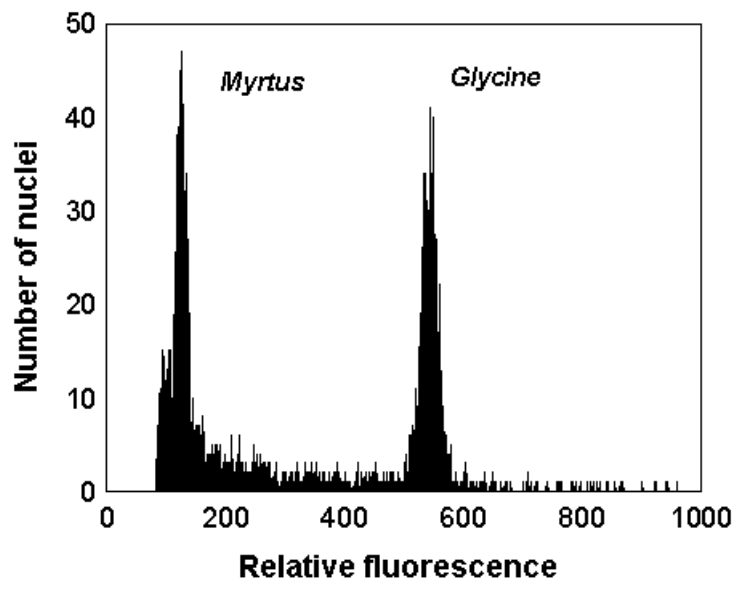

Figure 2. Flow cytometric histogram of DAPI-stained nuclei isolated from wild myrtle (No. 31-05) and internal reference standard (Glycine max). 
CVs for the internal standard varied from 2.39 to $2.90 \%$; CVs for the sample were much larger, perhaps due to the presence of secondary metabolites of polyphenolic nature, and varied from 6.13 to $8.92 \%$. Relative fluorescence intensities (setting Glycine max as a unit value) in six cultivated genotypes ranged from 0.232 (in 31-06) to 0.238 (in 31-02), while the two wild genotypes both showed a fluorescence value of 0.231 . The intraspecific variation was thus negligible and amounted to about 3\%. Interestingly, wild genotypes showed slightly lower fluorescence values than their cultivated counterparts. Nevertheless, more representative myrtle sampling and higher resolution of flow cytometric analyses would be necessary to interpret the results as a genuine divergence in genome size.

Our findings indicate that the domestication processes such as selection over time have resulted in differences between cultivated and wild forms of myrtle. During this process, white-fruited types with large and less acidic berries were preferred. Both wild and cultivated genotypes show similar karyological characteristics, indicating that genome duplication and/ or divergence in the number of chromosomes is not associated with myrtle domestication.

\section{ACKNOWLEDGMENTS}

We thank João Loureiro for his help with some flow cytometric analyses. Flow cytometric analyses were supported by projects MSM \#0021620828 (Ministry of Education, Youth and Sports of the Czech Republic) and \#AV0Z60050516 (Academy of Sciences of the Czech Republic).

\section{REFERENCES}

Aronne G and Russo D (1997). Carnivorous mammals as seed dispersers of Myrtus communis (Myrtaceae) in the Mediterranean shrublands. Plant Biosyst. 131: 189-195.

Baytop T (1997). Dictionary of Plant Names in Turkish. Türk Dil Kurumu Yayınları, Ankara.

Baytop T (1999). Therapy with Medicinal Pants in Turkey (Past and Present). Nobel Medical Press, Istanbul.

Bruna S, Portis E, Cervelli C, De Benedetti L, et al. (2007). AFLP-based genetic relationships in the Mediterranean myrtle (Myrtus communis L.). Sci. Hortic. 113: 370-375.

Canhoto JM, Lopes ML and Cruz GS (1999). Somatic embryogenesis and plant regeneration in myrtle (Myrtaceae). Plant Cell Tiss. Org. Cult. 57: 13-21.

Ciccarelli D, Garbari F and Pagni AM (2008). The flower of Myrtus communis (Myrtaceae): Secretory structures, unicellular papillae, and their ecological role. Flora 203: 85-93.

Doležel J, Doleželová M and Novák FJ (1994). Flow cytometric estimation of nuclear DNA amount in diploid bananas (Musa acuminata and M. balbisiana). Biol. Plantarum 36: 351-357.

Grant V (1963). The Origin of Adaptations. Columbia University Press, New York.

Hancock JF (2005). Contributions of domesticated plant studies to our understanding of plant evolution. Ann. Bot. 96: 953-963.

Klein JD, Cohen S and Hebbe Y (2000). Seasonal variation in rooting ability of myrtle (Myrtus communis L.) cuttings. Sci. Hortic. 83: 71-76.

Şerçe S, Şimşek Ö, Gündüz K, Aka-Kaçar Y, et al. (2008). Relationships among myrtle accessions from Turkey as revealed by fruit characteristics and RAPD. Roum. Biotechnol. Lett. 13: 4054-4065.

Soltis DE and Soltis PS (1999). Polyploidy: recurrent formation and genome evolution. Trends Ecol. Evol. 14: 348-352.

Suda J, Krahulcová A, Trávníček P, Rosenbaumova R, et al. (2007). Genome size variation and species relationships in Hieracium sub-genus Pilosella (Asteraceae) as inferred by flow cytometry. Ann. Bot. 100: 1323-1335.

Traveset A, Riera N and Mas RE (2001). Ecology of fruit-coloured polymorphism in Myrtus communis and differential effects of birds and mammals on seed germination and seedling growth. J. Ecol. 89: 749-760. 